\title{
EVALUATION OF MICROLEAKAGE OF SILVER NANOPARTICLE-ADDED PIT AND FISSURE SEALANT IN PERMANENT TEETH (IN-VITRO STUDY)
}

Sarah M. khairy ${ }^{1 * B D S}$, Magda M. El-Tekeya ${ }^{2 P h D}$, Niveen S. Bakry ${ }^{2 h h D}$, Mostafa N. Aboshelib ${ }^{3 h h D}$.

\begin{abstract}
INTRODUCTION: Silver has long been recognized for its antimicrobial effect on a wide spectrum of microorganisms. Consequently, silver nanoparticles became among the most common therapeutic nanoparticles under research in the field of caries prevention. Pit-and-fissure sealants are among the major components in the field of caries prevention which could have an additional antibacterial benefit through silver nanoparticles addition.

OBJECTIVES: The aim of the study was to evaluate, in-vitro, the marginal seal of silver nanoparticle-added pits and fissure sealant in comparison to the conventional sealant in permanent teeth.

MATERIALS AND METHODS: Thirty sound premolar teeth extracted for orthodontic purposes were randomly assigned into two main groups; Group I $(n=15)$ for silver nanoparticle-added ClinproTM sealant and Group II $(n=15)$ for the conventional ClinproTM sealant. Silver nanoparticle-added sealant was prepared by mixing the contents of one syringe of ClinproTM sealant to silver nanopowder of particle size 50$80 \mathrm{~nm}$ at a concentration of $6.25 \mu \mathrm{g} / \mathrm{ml}$. For microleakage testing, after sealant application and thermocycling for 500 thermal cycles, the sealed teeth was immersed into $1 \%$ methylene blue solution for $24 \mathrm{~h}$, sectioned longitudinally in a bucco-lingual direction and then examined under stereomicroscope for dye penetration assessment at x60 magnification.
\end{abstract}

RESULTS: Using Mann Whitney U test there was no statistically significant difference in microleakage between both groups ( $\mathrm{P}=0.325)$

CONCLUSION: Addition of silver nanoparticles to pit-and-fissure sealant did not affect its sealing ability.

KEYWORDS: Caries, Pit-and-fissure sealants, Silver nanoparticles, Microleakage.

RUNNING TITLE: Microleakage of silver nanoparticle-added fissure sealant.

1 Instructor of Pediatric Dentistry, Department of Pediatric Dentistry and Dental Public Health, Faculty of Dentistry, Alexandria University, Egypt

2 Professor of Pediatric Dentistry, Department of Pediatric Dentistry and Dental Public Health, Faculty of Dentistry, Alexandria University, Egypt.

3 Professor of dental materials, Department of dental materials, Faculty of Dentistry, Alexandria University, Egypt.

*Corresponding author

E-mail:sarahkhairy7@gmial.com

\section{INTRODUCTION}

Caries is one of the most prevalent chronic diseases affecting human kind, accounting for about $60 \%$ to $90 \%$ of school children and the majority of adults worldwide (1). Occlusal surfaces are the most susceptible surfaces for caries lesions representing $80-90 \%$ of caries present in permanent teeth (2). Pit-and-fissure sealants have become among the major components of the comprehensive caries management approach. These materials penetrate and seal the imperfections in the occlusal pits and fissures, forming a physical barrier that acts as a protective layer preventing cariogenic bacteria and their products from accessing these surfaces (3).

Although the advances obtained in restorative dental materials, current dental resins including pit-and-fissure sealants are mostly bioinert with minimal interaction with oral biofilms (4). Therefore, developing a new generation of bioactive materials with additional functional or therapeutic capabilities to aid in caries management is being adopted $(4,5)$. This could be achieved through the innovation of nanotechnology.

Nanotechnology is the science of manipulating matter at a nanometer scale $(<100 \mathrm{~nm}$ in diameter) with exhibition of novel physical, optical, chemical, and biological properties (13). Preventive dentistry has become one of the major dental disciplines that can benefit from the application of many therapeutic nanoparticles that can fight microbial biofilm formation and effectively remineralize initial dental decay $(10,12)$.

Silver nanoparticles (AgNPs) have been recognized for their antibacterial property $(6,7)$. In the year 2008(8), HernándezSierra et al determined the antibacterial effect of AgNPs against streptococcus mutans with a minimum inhibitory concentration of $4.86 \pm 2.71 \mu \mathrm{g} / \mathrm{ml}$ and a minimum bactericidal concentration of $6.25 \mu \mathrm{g} / \mathrm{ml}$. In addition, several studies have shown that AgNPs exihibit a synergistic effect to fluoride through inhibition of bacterial action of acid production in dental plaque allowing the fluoride component to enhance the net remineralization of dental structures (9, 10). Moreover, AgNPs do not lead to color change of dental tissues in contrary to other materials of similar effect such as silver diamine fluoride $(11,12)$.

Dental resins with addition of silver nanoparticles have been introduced into research field. In 2014 (13), Das Neves et al evaluated physical properties and antibacterial activity of a light-activated composite modified with silver nanoparticles at two different concentrations ( $0.3 \%$ wt and $0.6 \%$ wt). It was concluded that the composite modified with $0.3 \%$ wt of AgNPs was less conducive to biofilm growth, without 
compromising the strength in compression and surface roughness when compared to the conventional composite.

Pit-and-fissure sealants could have an additional antibacterial benefit through the addition of AgNPs $(9,14,15)$. The caries preventive feature of dental sealants depends on the ability to thoroughly fill pits and fissures with adequate marginal integrity at the enamel- sealant interface as marginal microleakage allows passage of bacteria, fluids, ions and molecules to prompt caries progression (16). MoralesQuirogas et al in 2014 (14) studied the effect of silver nanoparticles addition to pit- and-fissure sealant. It was found that; there was no significant difference with respect to marginal seal or microleakage in comparison to the conventional sealant when applied to primary teeth.

The aim of the present study was to evaluate the effect of the addition of silver nanoparticles to pit-and-fissure sealant on the microleakage in comparison to the conventional sealant when applied to permanent teeth. The null hypothesis of the study was that there would be no significant difference in microleakage between silver nanoparticle-added sealant and conventional sealant when applied to permanent teeth.

\section{MATERIALS AND METHODS}

This study was an experimental in-vitro study, which was approved by the Scientific Research Ethical Committee, Faculty of Dentistry, Alexandria University, Egypt.

Thirty sound premolars extracted for orthodontic purposes that were free from cracks, caries, restorations or any developmental defects were included in the study. The occlusal surfaces of the teeth were cleaned with fluoride free prophylaxis paste using brushes at low speed and stored in distilled water until use. Teeth were randomly divided into two groups. Group I: (study group) $(n=15)$ for silver nanoparticle-added Clinpro ${ }^{\mathrm{TM}}$ sealant and group II: (control group) $(n=15)$ for the conventional Clinpro ${ }^{\mathrm{TM}}$ sealant.

Preparation of silver nanoparticle-added sealant involved extraction of the entire content of one syringe of Clinpro $^{\mathrm{TM}}$ sealant (3M ESPE, St. Paul, MN, USA) from its container to a clean dry capsule. Then, it was mixed with silver nanopowder of particle size from 50-80 nm (US- Research-Nanomaterials, Inc.) at a concentration of $6.45 \mu \mathrm{g} / \mathrm{mL}$ using an amalgamator (de GotzenS.R.l Italy) for 10 seconds to obtain a homogenous mix. Silver nanoparticles-added Clinpro ${ }^{\mathrm{TM}}$ Sealant was reloaded immediately to the original syringe in a dark container $(9,14)$.

\section{Microleakage Test Procedure}

The root apices of the teeth (fifteen for each group) were sealed using sticky wax. Each tooth was mounted in selfcuring acrylic resin using rounded copper moulds with the occlusal surface facing upwards and perpendicular to the long axis of the block. The occlusal surface of each tooth was etched with $32 \%$ by weight phosphoric acid gel (3M ESPE, St. Paul, MN, USA) for $15 \mathrm{sec}$, rinsed for $10 \mathrm{sec}$ and then airdried for 5 sec following the manufacturer's instructions. In group I: Silver nanoparicle-added sealant was applied and light cured for 40 seconds (15). In group II: Conventional Sealant was applied and light-cured for 20 seconds according to the manufacturer instructions. Both types of sealant were cured using LED light curing system (Ivoclar Vivadent, Germany). All teeth were then subjected to 500 thermal cycles, with changing temperature between $5^{\circ} \pm \mathrm{C}$ and $55 \pm 5^{\circ} \mathrm{C}$ in a water bath with a dwell time of 30 seconds (17).

All teeth surfaces were coated with two layers of nail varnish except for $1.5 \mathrm{~mm}$ of the sealant margins. Teeth were then immersed in a $1 \%$ solution of methylene blue for 24 hours (18). Teeth were rinsed with distilled water, dried and sectioned longitudinally in a bucco-lingual direction using a water-cooled diamond disk to provide two sections for each tooth. The extent of dye penetration at sealant/enamel interface was assessed by a single examiner using the light stereomicroscope (OLYMPUS SZ II. Olympus optical Co. Tokyo, Japan) under x60 magnification.

A ranked scale described by Overbo and Raadal, (1990)(19) was used to score dye penetration:(0) no dye penetration; (1) dye penetration limited to the outer half of the sealant; (2) leakage up to the inner half of the sealant; (3) dye penetration extending to the underlying fissure. Both sections were scored and the section with the greatest dye infiltration was considered the score of dye penetration for this tooth.

Prior to the study, training on the application of scoring criteria was done under supervision of a gold standard (second supervisor) on a group of 10 specimens with all levels of dye penetration. Calibration was as done by examining another 20 specimens with one week interval. The kappa statistic was used to determine the intra-examiner reliability for evaluating the degree of dye penetration. For both groups, there was a significant very good agreement between two assessments of microleakage as $\mathrm{K}=0.95$ at $95 \% \mathrm{CI}, \mathrm{P}<0.001$ which indicates consistency of the examiner in the application of scoring criteria overtime.

\section{Statistical analysis}

Sample size was calculated using the following assumptions: Using the microleakage values reported by Bahrololoomi et al in 2011 (16) with an Alpha error $=5 \%$, power $=80 \%$, the minimum required sample size per group was calculated to be 13 . It was increased by $10 \%$ to make up for lab error to reach $n=15$ per subgroup.

A non-parametric Mann Whitney U test was performed to identify statistically significant differences between both study and control groups. The level of significance was set at $\mathrm{P}<0.05$, with a statistical power of $80 \%$.

\section{RESULTS}

The distribution of dye penetration scores among study and control groups is presented in table 1 and figures 1-4. There was no dye penetration (Score 0 ) in $60 \%$ of specimens sealed with silver nanoparticle-added sealant (group I) and in $40 \%$ of specimens sealed with the conventional Clinpro $^{\mathrm{TM}}$ sealant (group II). Median score of group I was 0 and that of group II was 2. Using Mann Whitney $U$ test; there was no statistically significant difference in microleakage between both groups $(\mathrm{p}=0.325)$. 
Table (1) : Comparison of microleakage scores between group I (test group) and group II (control group).

\begin{tabular}{|c|c|c|c|c||}
\hline \multirow{2}{*}{$\begin{array}{c}\text { microleakage } \\
\text { scores }\end{array}$} & \multicolumn{2}{|c|}{$\begin{array}{c}\text { Subgroup IA } \\
(\mathbf{n}=15)\end{array}$} & \multicolumn{2}{c|}{$\begin{array}{c}\text { Subgroup IIA } \\
(\mathbf{n}=15)\end{array}$} \\
\cline { 2 - 6 } & No & $\mathbf{\%}$ & No & \% \\
\hline $\mathbf{0}$ & 9 & 60 & 6 & 40 \\
\hline $\mathbf{1}$ & 1 & 6.7 & 1 & 6.7 \\
\hline $\mathbf{2}$ & 2 & 13.3 & 3 & 20 \\
\hline $\mathbf{3}$ & 3 & 20 & 5 & 33.3 \\
\hline $\begin{array}{c}\text { Median } \\
\text { (Min - Max) }\end{array}$ & \multicolumn{2}{|c|}{$\begin{array}{c}0 \\
(0-3)\end{array}$} & \multicolumn{2}{c||}{$\begin{array}{c}2 \\
(0-3)\end{array}$} \\
\hline $\begin{array}{c}\text { Test of } \\
\text { significance(p) }\end{array}$ & \multicolumn{3}{|c||}{$(\mathrm{U}=137, \mathrm{p}=0.325)$} \\
\hline
\end{tabular}

।U: Mann Whitney test

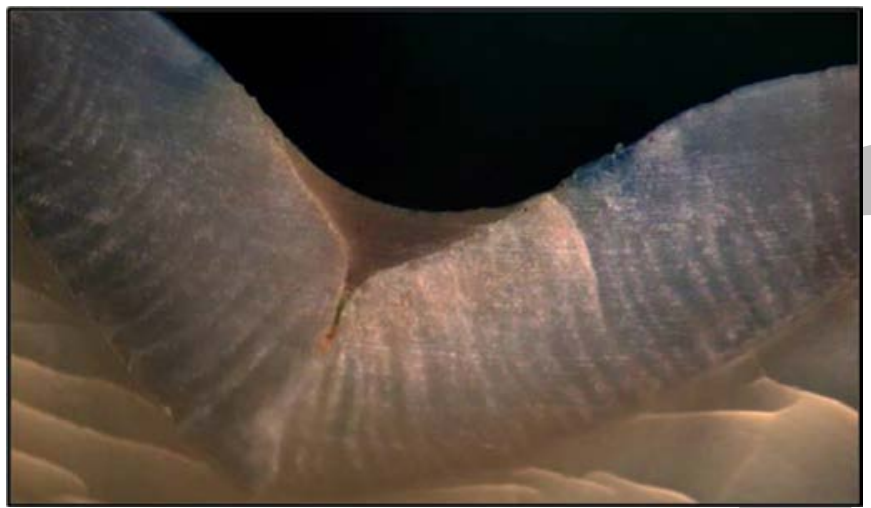

Figure (1): Score 0 of dye penetration in group

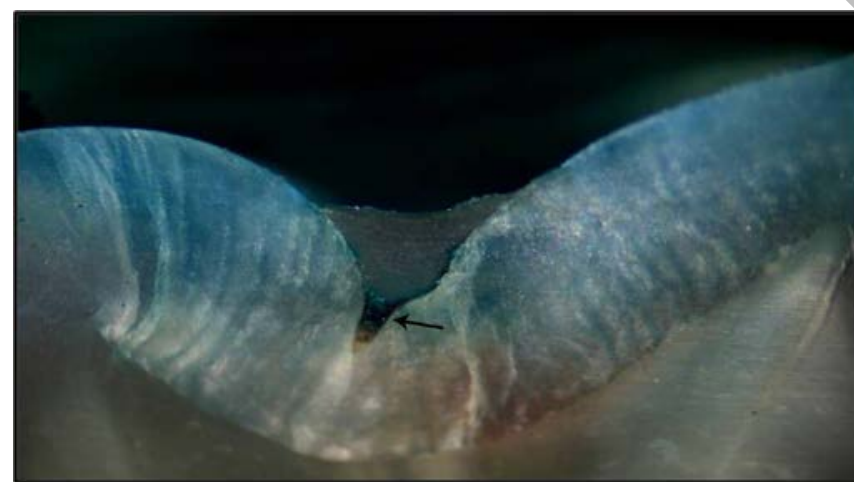

Figure (2): Score 3 of dye penetration in group I

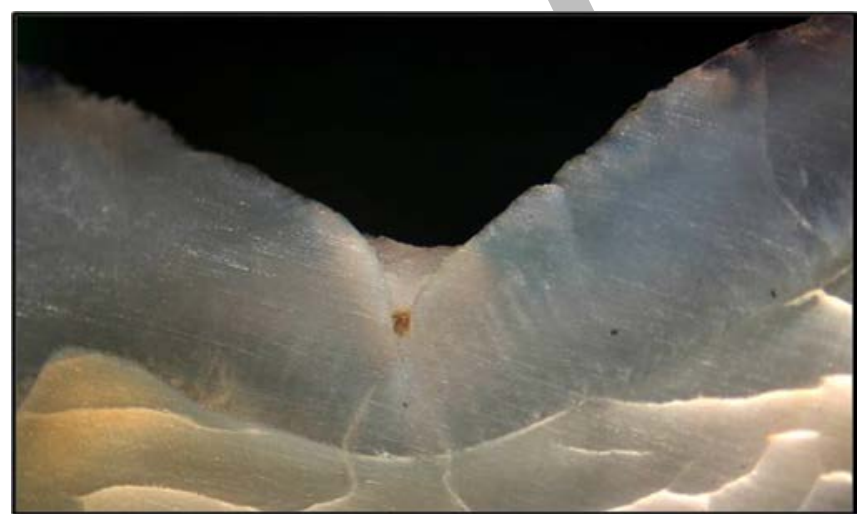

Figure (3): Showing score 0 of dye penetration in group II

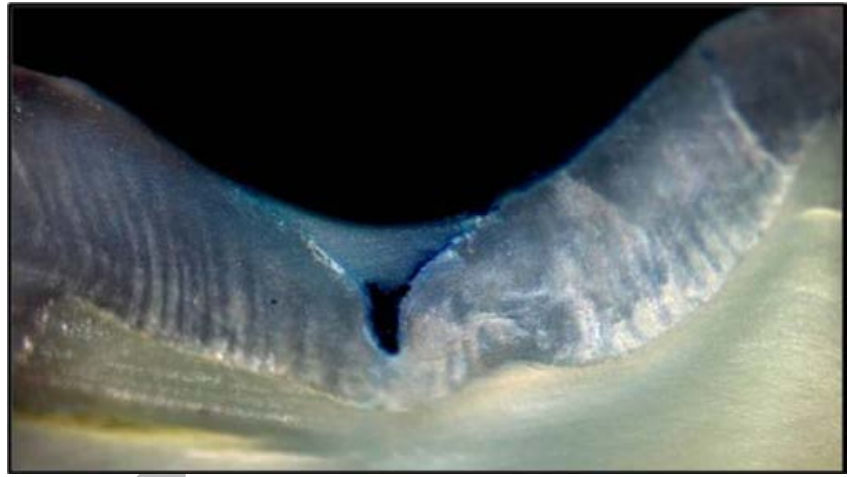

Figure (4): Showing score 3 of dye penetration in group II.

\section{DISCUSSION}

The contemporary approach of minimal intervention dentistry relies primarily on caries prevention and non-invasive management of incipient carious lesions (20). Pit-and-fissure sealants (PFS) have become among the major components in the comprehensive caries management approach (21).

The addition of silver nanoparticles (AgNPs) to PFS can increase the protective effect against the formation of carious lesions (14). Several studies clarified that silver in its nanoparticulated form possess an antimicrobial effect against Streptococcus mutans and lactobacilli $(8,23-26)$ which are considered the main microbial causative factor of dental caries (27). In addition, silver nanoparticles have a synergistic effect to fluoride by enhancing remineralization of incipient lesions (28) and arresting established lesions with the advantage of not staining teeth (11).

The preventive feature of dental sealants depends on the ability of the material to promote an appropriate sealing of pits and fissures with adequate marginal integrity at the enamel-sealant interface (16). Therefore, the aim of this study was to evaluate the marginal microleakage of silver nanoparticle-added Clinpro $^{\mathrm{TM}}$ pit-and-fissure sealant and compare it to the conventional Clinpro ${ }^{\mathrm{TM}}$ sealant.

In the present study, the type of sealant used was Clinpro ${ }^{\mathrm{TM}}$ pit-and-fissure sealant. It is a light cure, fluoride-releasing, unfilled, resin-based sealant with a color changing property in an attempt to facilitate detection of polymerization (29). It was mixed with silver nanoparticles of particle size of 5080nm according to Salas-López et al in 2017(9). HernandezSierra et al in 2011(30) evaluated the possible toxic cellular effects of different concentrations and sizes of silver nanoparticles. It was demonstrated that silver nanoparticles of size more than $20 \mathrm{~nm}$ didn't modify the viability of human primary culture cells isolated from human periodontal tissue. In addition, silver nanopowder was added to the sealant at a concentration of $6.25 \mu \mathrm{g} / \mathrm{ml}$ according to Morales-Quiroga et al in 2014 (14). Hernandez-Sierra et al in 2008 (8) studied the antibacterial properties of silver nanoparticles on streptococcus mutans. It was found that, the minimum bactericidal concentration of silver nanoparticles was $6.25 \mu \mathrm{g} / \mathrm{ml}$. Moreover, in 2012 (31), Martínez-Gutierrez et al demonstrated that exposure of AgNPs at low concentrations up to $6.25 \mu \mathrm{g} / \mathrm{ml}$ exhibited only minimal cytotoxic effects on macrophages and inflammatory cells. Moreover, it was found that low concentration of silver nanoparticles did not 
cause staining of tooth structure (11). Consequently, silver nanoparticles could have high antimicrobial effect against $S$. mutans at a low and safe concentration without affecting the color of tooth structure.

In the present study, the curing time of the silver nanoparticle-added sealant was increased to 40 seconds according to Al-Niami et al in 2015 (15). This was in accordance with Durner et al in 2011 (32) who showed an interaction between AgNPs and the curing light in the form of scattering of light photons, absorption of the photons ,electron transfer from or to the silver nanoparticles or formation of complexes with silver ions. This could affect the degree of polymerization of monomers.

In the present study, thermocycling was used to evaluate aging under in vitro conditions. Thermal changes controlled in a laboratory environment have been used to replicate the oral environment and to imitate the normal aging process $(16,33)$. During thermocycling, repetitive contractionexpansion stresses are generated at the interface between resin and tooth structrue. This is mainly attributed to higher contraction-expansion coefficient of the resin material than that of tooth structure which may lead to crack propagation along the resin-tooth structure interface (34).

In the present study, silver nanoparticle-added sealant group showed microleakage in only $40 \%$ of the specimens while it occurred in $60 \%$ of the specimens sealed by the conventional Clinpro $^{\mathrm{TM}}$ sealant. However, this difference was not statistically significant $(\mathrm{p}=0.325)$. The possible explanation of these results is that; when added to some polymers, AgNPs could enhance the thermal stability of the resultant nano-polymer (35). This could possibly decrease marginal defects between the material and tooth substrate especially when exposed to thermocycling.

These results were supported by Morales-Quiroga et al in 2014 (14) who reported no significant difference between the marginal seal and microleakage of Clinpro ${ }^{\mathrm{TM}}$ modified with AgNPs when compared to the conventional sealant in primary molars. It was also in agreement with Salas-López et al in 2017 (9) who demonestrated no significant difference of microleakage scores between silver nanoparticle-added sealant mixed with silver nanopowder at a concentration of $98 \mu \mathrm{g} / \mathrm{ml}$ and the conventional sealant in permanent teeth.

Although the present study methodology attempted to simulate the clinical conditions by prevention of specimen dehydration and thermocycling to simulate aging, a possible limitation would be that extracted teeth lack the pulp pressure and intertubular fluid pressure present in natural teeth (36). This could have an influence on tooth moisture level, affecting microleakage at tooth restoration interface. Another limitation of this study was that it was an in vitro study and moisture control was easy to achieve.

The overall results of this study necessitated the acceptance of the null hypothesis that there is no difference in microleakage between silver nanoparticle-addition to Clinpro ${ }^{\mathrm{TM}}$ pit-andfissure sealant and the conventional sealant when applied to permanent teeth.

\section{CONCLUSION}

Within the limitation of this study, it was concluded that, the addition of silver nanoparticles to pit-and -fissure sealant did not affect its sealing ability.

\section{CONFLICT OF INTEREST}

The authors declare that they have no conflict of interest.

\section{REFERENCE}

1. Selwitz RH, Ismail AI, Pitts NB. Dental caries. Lancet 2007; 369:51-9.

2. American Academy of Pediatric Dentistry. Guideline on Restorative Dentistry. Reference Manual. Pediatr Dent. 2016;37:230-41.

3. Wright JT, Tampi MP, Graham L, Estrich C, CrallJJ, Fontana M, et al. Sealants for preventing and arresting pit-and-fissure occlusal caries in primary and permanent molars. Pediatr Dent. 2016; 38:282-308.

4. Cheng L, Zhang K, Zhang N, Melo MA, Weir MD, Zhou XD, Bai YX, Reynolds MA, Xu HH. Developing a new generation of antimicrobial and bioactive dental resins. J Dent Res. 2017;96:855-63.

5. Melo MA, Guedes SF, Xu HH, Rodrigues LK. Nanotechnology-based restorative materials for dental caries management. Trends biotechnol. 2013; 31:459-67.

6. Prabhu S, Poulose EK. Silver nanoparticles: mechanism of antimicrobial action, synthesis, medical applications, and toxicity effects. Int Nano Lett 2012;2:32.

7. Rai M, Yadav A, Gade A. Silver nanoparticles as a new generation of antimicrobials. Biotechnol Adv. 2009;27:76-83.

8. Hernández-Sierra JF, Ruiz F, Pena DC, MartínezGutiérrez F, Martínez AE, Guillén AD, et al. The antimicrobial sensitivity of Streptococcus mutans to nanoparticles of silver, zinc oxide, and gold. Nanomedicine. 2008;4:237-40.

9. Salas-López EK, Pierdant-Pérez M, Hernández-Sierra JF, Ruíz F, Mandeville P, Pozos-Guillén AJ. Effect of silver nanoparticle-added pit and fissure sealant in the prevention of dental caries in children. J Clin Pediatr Dent. 2017;41:48-52.

10. Targino AGR, Flores MAP, dos Santos Junior VE, Bezerra FdGB, de Luna Freire H, Galembeck A, et al. An innovative approach to treating dental decay in children. A new anti-caries agent. J Mater Sci Mater Med. 2014;25:2041-7.

11. Hernández-Sierra JF, Ruíz F, Castanedo-Cázares JP, Martinez-Ruiz V, Mandeville P, Pierdant-Pérez M, et al. In vitro determination of the chromatic effect of a silver nanoparticles solution linked to the Gantrez S-97 copolymer on tooth enamel. J Clin Pediatr Dent. 2010;35:65-8.

12. Rosenblatt A, Stamford TC, Niederman R. Silver diamine fluoride: A caries "silver-fluoride bullet”. J Dent Res. 2009;88:116-25.

13. Das Neves PB, Agnelli JA, Kurachi C, de Souza CW. Addition of silver nanoparticles to composite resin: effect on physical and bactericidal properties in vitro. Braz Dent J. 2014;25:141-5. 
14. Morales-Quiroga E, Martínez-Sumarán A, HernándezSierra JF. Evaluation of marginal seal and microleakage of a sealant modified with silver nanoparticles in primary molars :In vitro study. ODOVTOS Int J Dent Sc. 2014;16:107-13.

15. Al-Naimi RJ, Al-Alousi WS, Al-Nema M. Effect of silver and zinc oxide nanoparticle addition on microhardness and depth of cure of resin based pit and fissure sealants. IJERSTE. 2015; 4:157-63.

16. Bahrololoomi Z, Soleymani A, Heydari Z. In vitro comparison of microleakage of two materials used as pit and fissure sealants. J Dent Res Dent Clin Dent Prospects. 2011;5:83-6.

17. Douglas W, Fields R, Fundingsland J. A comparison between the microleakage of direct and indirect composite restorative systems. J Dent. 1989;17:184-8.

18. Arcoria C, Fisher M, Wagner M. Microleakage in alloyglass ionomer lined amalgam restorations after thermocycling. J Oral Rehabil.1991;18:9-14.

19. Övrebö RC, Raadal M. Microleakage in fissures sealed with resin or glass ionomer cement. Eur J Oral Sci. 1990;98:66-9.

20. Liu BY, Lo EC, Chu CH, Lin HC. Randomized trial on fluorides and sealants for fissure caries prevention. J Dent Res. 2012; 91:753-8.

21. Wright JT, Crall JJ, Fontana M, Gillette EJ, Nový BB, Dhar V, et al. Evidence-based clinical practice guideline for the use of pit-and-fissure sealants. American Academy of Pediatric Dentistry, American Dental Association. Pediatr Dent. 2016; 38:E120-36.

22. Ahovuo-Saloranta A, Forss H, Walsh T, Nordblad A, Mäkelä M, Worthington HV. Pit and fissure sealants for preventing dental decay in permanent teeth. Cochrane Database Syst Rev. 2017;7:CD001830.

23. Dos Santos Junior VE, Targino AG, Flores MA, Rodríguez-Díaz JM, Teixeira JA, Heimer MV, et al. Antimicrobial activity of silver nanoparticle colloids of different sizes and shapes against Streptococcus mutans. Res Chem Intermed. 2017;43:5889-99.

24. Espinosa-CristóbalLF, Martínez-Castañón GA, Martínez-Martínez RE, Loyola-Rodriguez JP, PatinoMarin N, Reyes-Macias JF, et al. Antibacterial effect of silver nanoparticles against Streptococcus mutans. Mater Lett. 2009;63:2603-6.

25. Azarsina M, Kasraei S, Yousefi-MashoufR, Dehghani N, Shirinzad M. The antibacterial properties of composite resin containing nanosilver against Streptococcus mutans and Lactobacillus. J Contemp Dent Pract. 2013;14:1014-8.
26. Kasraei S, Sami L, Hendi S, AliKhani MY, RezaeiSoufi L, KhamverdiZ. Antibacterial properties of composite resins incorporating silver and zinc oxide nanoparticles on Streptococcus mutans and Lactobacillus. Restor Dent Endod. 2014;39:109-14.

27. Loesche WJ. Role of Streptococcus Mutans in human dental decay. MicrobiolRev. 1986;50:353-80.

28. Girón CB, Mariel-Cárdenas J, Pierdant-Pérez M, Hernández-Sierra JF, Morales-Sánchez JE, Ruiz F. Effectiveness of a combined silver nanoparticles/fluoride varnish in dental remineralization in children: in vivo study. Superficies yvacío. 2017;30:1-24.

29. Rock W, Potts A, Marchment M, Clayton-Smith A, Galuszka M. The visibility of clear and opaque fissure sealants. Br Dent J. 1989;167:395-6.

30. Hernández-Sierra JF, Galicia-Cruz O, Salinas-Acosta A, Ruíz F, Pierdant-Pérez M, Pozos-Guillén A. In vitro cytotoxicity of silver nanoparticles on human periodontal fibroblasts. J Clin Pediatr Dent. 2011; 36:37-42.

31. Martinez-Gutierrez F, Thi EP, Silverman JM , de Oliveria CC , Svensson SL, Hoek AV, et al. Antibacterial activity, inflammatory response, coagulation and cytotoxicity effects of silver nanoparticles. Nanomedicine. 2012;8:328-36.

32. Durner J, Stojanovic M, Urcan E, Hickel R, Reichl F-X. Influence of silver nano-particles on monomer elution from light-cured composites. Dent Mater. 2011;27:631-6.

33. Frazer RA, Platt JA, Sanders BJ, Yepes JF, Jones JE. The Effect of Fluoride Varnish on Enamel Shear Bond Strength of Pit and Fissure Sealants. Pediatr Dent. 2017;39:155-8.

34. Koyuturk AE, Kusgoz A ,Ulker M, Yesilyurt C. Effects of mechanical and thermal aging on microleakage of different fissure sealants. Dent Mater J. 2008;27:795801.

35. Chou CW, Hsu SH, Wang PH. Biostability and biocompatibility of poly(ether)urethane containing gold or silver nanoparticles in a porcine model. J Biomed Mater Res A. 2008;84:785-94.

36. Guelmann M, Bonnin S, Primosch RE, Soderholm KJ. Microleakage and wall adaptation of conservative restorations. Am J Dent. 2002;15:407-11. 